Gazi Üniversitesi
Fen Bilimleri Dergisi
PART C: TASARIM VE TEKNOLOJI
dergipark.gov.tr/http-gujsc-gazi-edu-tr

\title{
Toz Metalurjisi Yöntemiyle Üretilen 7075 Al Alaşımlarında Mn Miktarının Aşınma Davranışlarına Etkisinin İncelenmesi
}

\author{
Musa YILDIRIM $^{1 *}$, Dursun ÖZYÜREK ${ }^{2}$ \\ Karabük Üniversitesi, Teknoloji Fakültesi, Endüstriyel Tasarım Mühendisliği Bölümü, Karabük, Türkiye. \\ Karabük Üniversitesi, Teknoloji Fakültesi, Imalat Mühendisliği Bölümü, Karabük, Türkiye.
}

Makale Bilgisi

Başvuru: 24/08/2017

Düzeltme:02/11/2017

Kabul: 20/11/2017

Anahtar Kelimeler

Toz Metalurjisi

AA7075

Mn miktart

sertlik,

aşınma

Keywords

Powder metallurgy

AA7075

Mn amount

hardness

wear

\section{$\ddot{\mathbf{O} z}$}

$\mathrm{Bu}$ çalışmada, toz metalürjisi yöntemiyle AA7075 alaşımına Mn ilave edilerek üretilen alaşımların mikro yapı, sertlik ve aşınma davranışları incelenmiştir. Alaşımlar, gaz atomize $7075 \mathrm{Al}$ alaşım tozlarına 4 farklı oranda (\%0,5, \%1, \%2 ve \% 3) Mn ilave edilerek mekanik karıștırma yöntemi ile üretilmiștir. Üretilen alaşım tozları soğuk preslenerek ön şekillendirildikten sonra atmosfer kontrollü ortamda sinterlenmiştir. Farklı miktarda Mn ilave edilerek üretilen numunelerin mikro yap1 incelemeleri taramalı elektron mikroskobuyla yapılmıştır. Sertlik ölçümleri makro sertlik cihazında, aşınma testleri pin-on-disk tipi aşınma cihazında $15 \mathrm{~N}$ yük altında dört farklı kayma mesafesinde test edilmiştir. Yapılan çalışmalar sonucunda alaşıma ilave edilen Mn miktarı arttıkça sertliğin arttığı bunun yanında aşınma testleri sonucu ağırlık kaybının azaldığı belirlenmiștir.

\section{An Investigation of The Effects of Mn Amount on Wear Behaviors of 7075Al Alloy Produced by Powder Metallurgy Method}

\begin{abstract}
In this study, microstructure, hardness and wear behaviors of $7075 \mathrm{Al}$ alloy with adding different amount of Mn were investigated produced by powder metallurgy method. In the scope of the study, four different amount of $\mathrm{Mn}(0.5 \%, 1 \%, 2 \%, 3 \%)$ was added to gas atomized 7075 $\mathrm{Al}$ powders and mechanical mixed. Mixed $\mathrm{Al}$ and $\mathrm{Mn}$ powders were pre-shaped by cold pressing. Then, they were sintered in an atmosphere controlled furnace. Microstructure examination was done by scanning electron microscope, hardness values were measured using macro hardness tester. The wear tests were performed by pin-on disc type wear test device under $15 \mathrm{~N}$ loads with four different sliding distances. As a result of the study, it was determined that the hardness values were increased by increasing amount of the Mn. In addition, wear loss were decreased with increasing Mn amount.
\end{abstract}

\section{GIIRIŞ (INTRODUCTION)}

Alüminyum alaşımları yoğunluk, korozyon direnci ve elektrik iletkenliği gibi üstün özelliklerinden dolayı, otomotiv sektörü başta olmak üzere endüstride yaygın olarak kullanılmaktadır. Alüminyum alaşımları içerisinde en yüksek dayanıma sahip 7XXX serisi alüminyum alaşımları, havacılık sektöründe uçakların gövde ve kanat yapımında kullanılmaktadır [1-3]. AA7075 alüminyum alaşımın 7XXX serisi alaşımlar içerisinde en yaygın kullanılan alaşım grubudur. İçerisinde \% 5-6 Zn \% 2-2,9 Mg ve \% 1.6 ya kadar bakır içerebilirler [4]. Bu alaşım grubuna uygulanan yaşlandırma 1sıl işlemi ile mukavemet değerleri yükseltilebilmektedir. Yaşlandırma sertleştirmesi, bazı alüminyum alaşımlarının sertliğini ve aşınma direncini arttırmak için uygulanan alternatif yöntemlerden biridir. Alaşımların bileşimi aşınma davranışı için önemlidir. 7075 alüminyum alaşımlarının en önemli özelliği, yaşlandırılabilir olmasıdır.[57]. Ayrıca bu alaşıma ilave edilen elementler sayesinde dayanımı arttırmaktadır. $\mathrm{Bu}$ alaşım elementlerinden biriside Mn'dır. 6000, 7000 ve 8000 serisine sahip alüminyum alaşımlarında ilave edilen Mn'ın, sünekliliği düşürmeden çekme dayanımını arttırdığı belirtilmektedir [8]. AA7075 alaşımları dövme, döküm, ekstrüzyon, yarı katı gibi yöntemler ile üretilebilmektedir. Ayrıca son yıllarda toz metalürjisi yöntemi kullanılarak yapılan çalışmalar mevcuttur $[9,10]$. Toz metalürjisi yönteminde son 
şekilde veya son şekle yakın parça üretimi yapılabilmektedir. Ayrıca alüminyum alaşımlarında çözünebilirliği sınırlı olan (döküm metoduyla üretilemeyen) alaşım elementleri ve takviye fazları ilavesi ile çeşitli alaşımlar ve kompozitler üretilebilmektedir. Böylece karmaşık şekilli parçaların üretilmesi daha kolay ve ucuz olabilmektedir.

Aşınma, birlikte hareket eden parçaların sürtünmesinden kaynaklanan ve önemli bir yüzey hasarı olarak tanımlanan bir problemdir. Aşınma, çeşitli endüstriyel alanlarda yaygın olarak görülen ve sistemde verimliliğin azalmasına neden olan sorunlardan biridir. Güç kaybı, yakıt tüketimi nedeniyle bileşenlerin sık değiştirilmesini gerektirmektedir [5]. Malzemelerin aşınma davranışı, çalışma sırasında çeşitli parametrelere ve koşullara bağlıdır. Yük, hız veya çevresel koşullar, metal ve alaşımının aşınma performansı üzerinde büyük etkiye sahiptir [6,11-13]. Bu perspektiften bakıldığında, alüminyum alaşımlarının aşınma davranışı çok fazla ilgi görmektedir [14-16]. Metalik parçaların birbiri üzerinde kayması sırasında sünek olmaları nedeniyle, alüminyum alaşımlarının yüzeylerinde plastik deformasyona meydana gelmektedir. Bu konuda pek çok çalışma yapılmasına rağmen, alüminyum alaşımlarının aşınma mekanizması çok net değildir. Bu malzemelerde en iyi aşınma direncinin ortaya konabilmesi için, daha detaylı çalışmalara ihtiyaç duyulmaktadır. Bu nedenle, bu çalışmada toz metalürjisi yöntemiyle sıvı içerisinde çözünebilirliği sınırlı olan Mn'ın toz metalurjisi yöntemiyle AA7075 Al alaşımına ilave edilmesiyle üretilen alaşımların mikro yapı sertlik ve aşınma davranışlarına etkisi incelenmiştir.

\section{MALZEME VE METOT (MATERIAL AND METHOD)}

Deneysel çalışmalarda kullanılan ve kimyasal bileşimi Tablo 1'de verilen gaz atomize AA7075 alaşımına dört farklı (\% 0.5, \%1, \%2 ve \% 3 (\%ağırlık)) oranda Mn $(\leq 100 \mu \mathrm{m})$ ilave edilerek görüntüsü Şekil 1'de verilen SPEX tipi (8000 M MIXER/MILL) mekanik alaşımlama/mekanik ögütme (MA/MÖ) cihazında tungsten karbür öğütme haznesinde $10 \mathrm{~mm}$ çapa sahip paslanmaz çelik bilyeler ile 10:1 bilye- toz oranı kullanılarak 60 dakika süre ile mekanik karıştırma yapılmıştır. Daha sonra bu tozlar $650 \mathrm{MPa}$ basınç altında soğuk preslenerek $10 \mathrm{~mm}$ çapında ve $7 \mathrm{~mm}$ yüksekliğinde ön şekillendirilmiş numuneler elde edilmiştir. Elde edilen bu numuneler atmosfer kontrollü (argon gazı altında) firın içerisinde $595^{\circ} \mathrm{C}$ 'de 1 saat sinterlenerek firın ortamında soğutulmuştur. Sinterleme işlemleri sonunda üretilen numuneler standart metalografik işlemler sonrası $2 \mathrm{ml}(\mathrm{HF}), 90 \mathrm{ml}$ saf su, $5 \mathrm{ml}$ (HNO3), $3 \mathrm{ml}$ (HCl) solüsyonu ile 50-60 sn dağlanarak mikro yapıları, taramalı elektron mikroskobuyla incelenmiştir. Sertlik ölçümleri bilye çapı $2,5 \mathrm{~mm}$ ve uygulanan yük $31,25 \mathrm{kgf}$ olan Brinell sertlik ölçüm cihazında yapılmıştır. Her bir numuneden 3 farklı noktadan sertlik ölçümü yapılarak ortalama sertlik değerleri belirlenmiştir. Yoğunluk ölçümleri Precisa XB200h marka 1/10000 g hassasiyetteki hassas terazide Archimend's prensibine göre yapılmıştır. Aşınma testleri görüntüsü Şekil 2'de verilen pin-on disc tipi aşınma cihazında ASTM-G99-05 standardında oda sıcaklığında ve kuru şartlarda $1 \mathrm{~ms}^{-1}$ kayma hızı ile $15 \mathrm{~N}$ yük altında dört farklı kayma mesafesinde (400-800-1200-1600 m) yapılmıştır. Aşınma testlerinde karşılık diski olarak AISI 4140 malzemeden yapılmıs ve Ø230 mm çapında, $20 \mathrm{~mm}$ kalınlığında ve 60-64 HRC sertliğinde çelik disk kullanılmıştır. Aynı yüzey kalitesi sağlanması için her test öncesinde hem numune hem de disk yüzeyleri aseton ile temizlenmiştir.

Tablo 1: AA7075 alaşımının kimyasal bileşimi (The chemical composition of AA7075 alloy)

\begin{tabular}{ccccccccccc}
\hline Element & $\mathrm{Zn}$ & $\mathrm{Mg}$ & $\mathrm{Cu}$ & $\mathrm{Mg}$ & $\mathrm{Fe}$ & $\mathrm{Cr}$ & $\mathrm{Si}$ & $\mathrm{Mn}$ & $\mathrm{Ti}$ & $\mathrm{Al}$ \\
\hline Ağırlık $(\%)$ & 5,16 & 2,19 & 1,30 & 2,19 & 0,28 & 0,19 & 0,17 & 0,15 & 0,009 & Kalan \\
\hline
\end{tabular}




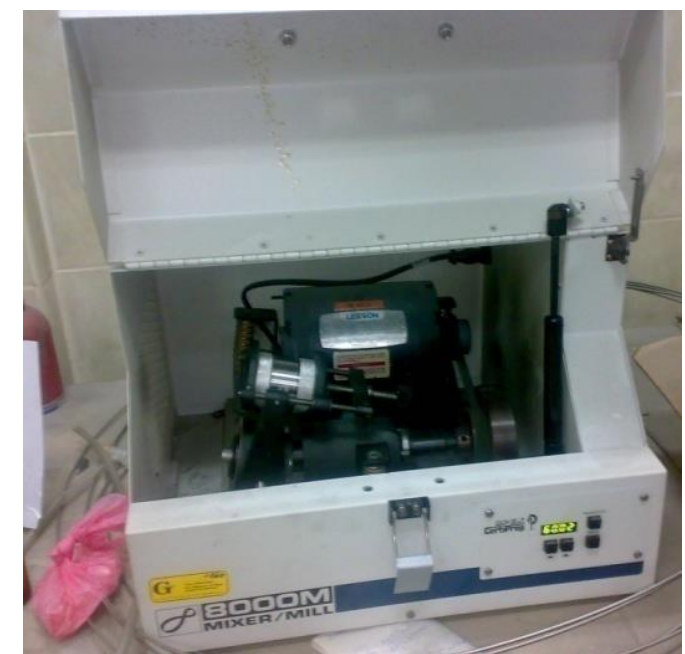

Şekil 1 Mekanik karıştırmada kullanılan öğütme cihazının görüntüsü (Image of milling device used in mechanical milling)

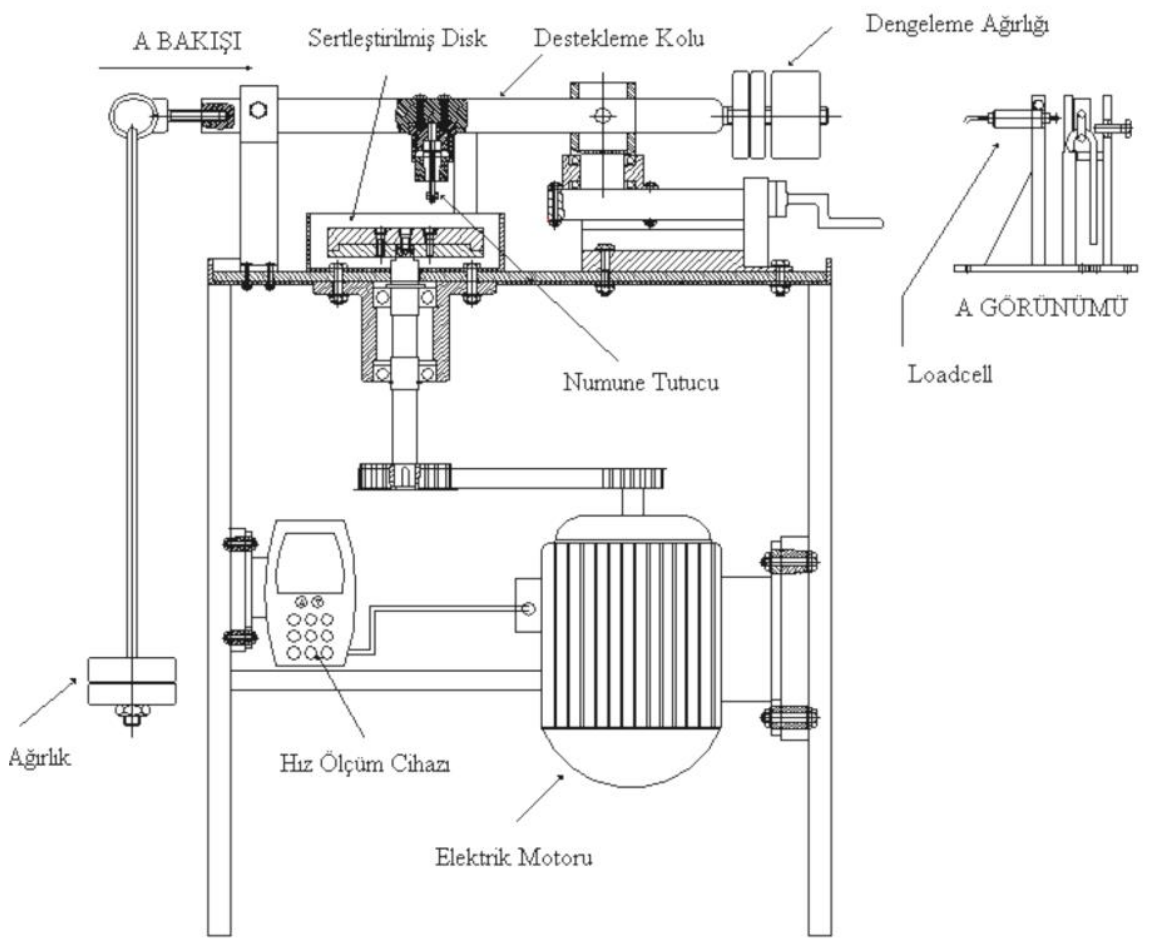

Şekil 2 Aşınma testlerinde kullanılan pin-on disk tipi aşınma cihazının şematik görüntüsü (the schematic view of pin -on disc type wear device used in wear tests)

\section{SONUÇLAR VE TARTIŞMA (RESULTS AND DISCUSSION)}

Dört farklı oranda Mn ilave edilerek üretilen alaşımların mikro yapı SEM görüntüleri Şekil 3'de \% 3 Mn içeren alaşımın EDS sonuçları ise Şekil 4'de verilmektedir. 


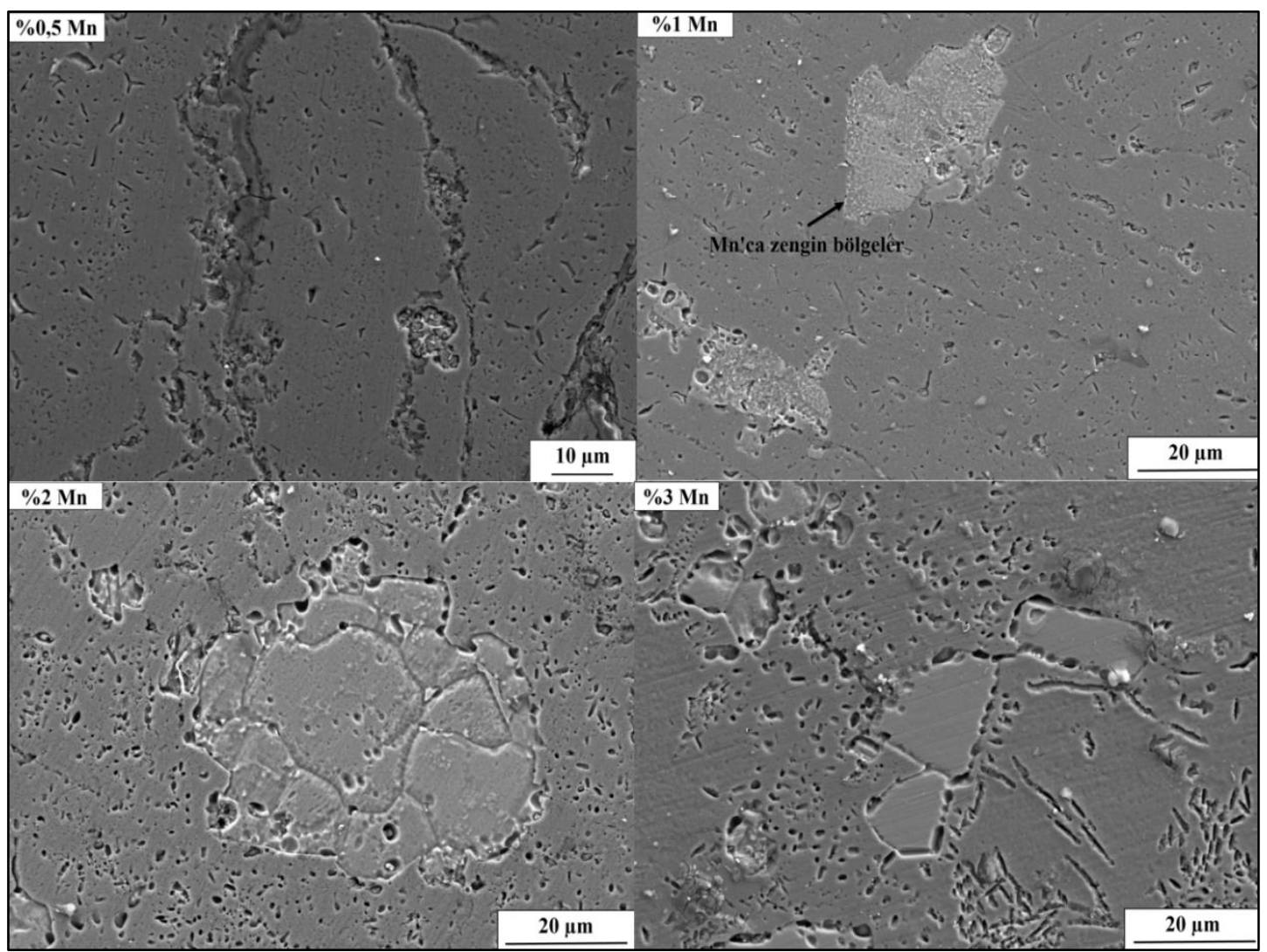

Şekil 3: Farklı oranlarda Mn ilave edilerek üretilen alaşımların mikro yapı SEM görüntüleri(SEM images of producedalloys with different amount of $\mathrm{Mn}$ )

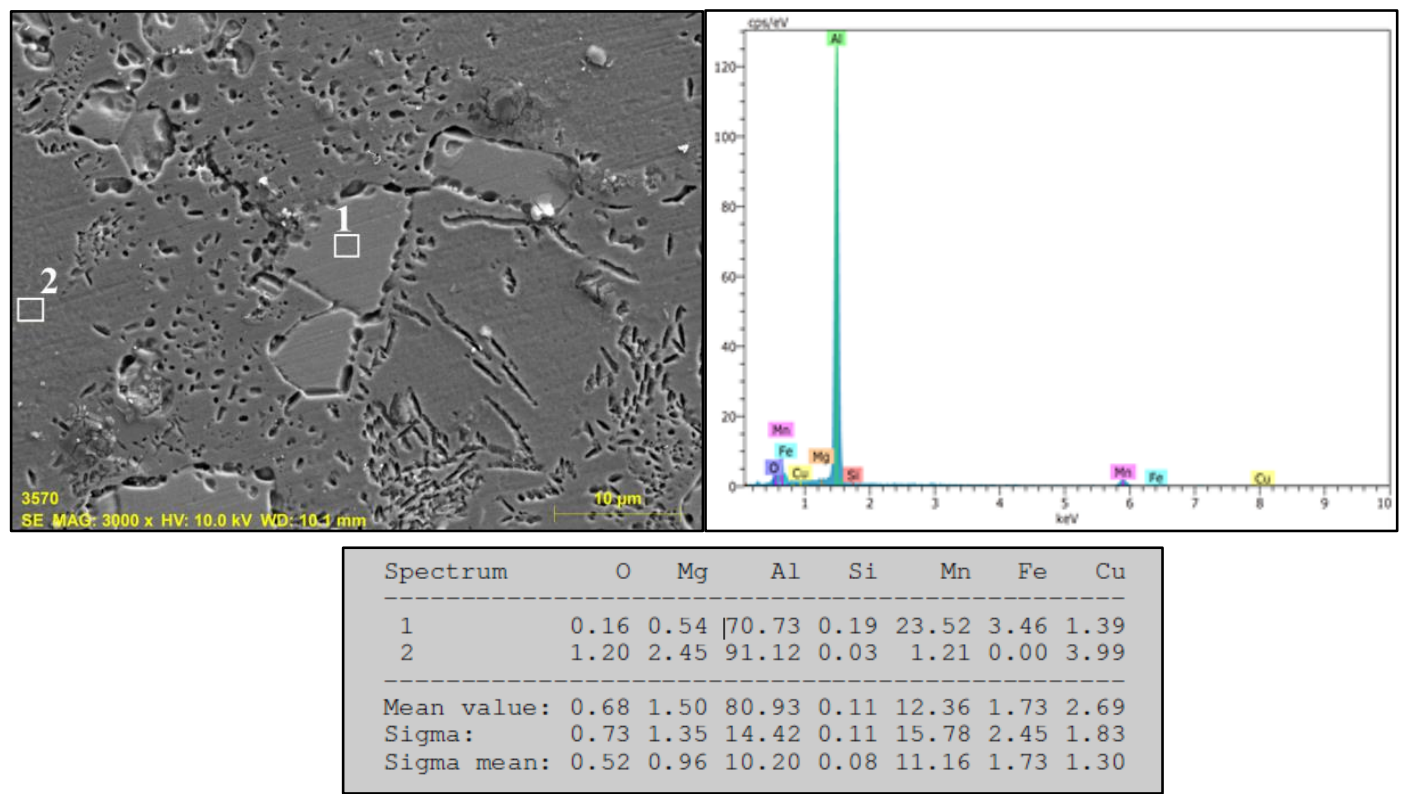

Şekil 4. \% 3 Mn içeren alaşımın EDS sonuçlar(EDS results of $3 \%$ Mn content alloy)

Şekil 3'de verilen SEM görüntüleri incelendiğinde, AA7075 alaşımında matris faz olan alüminyum ve Mn'ca zengin bölgelerin olduğu görülmektedir. Bu yapıların daha net tanımlanabilmesi için \% $3 \mathrm{Mn}$ içeren alaşımdan alınan EDS sonuçları Şekil 4'de verilmektedir. Şekil 4 'de verilen SEM ve EDS sonuçları incelendiğinde 1 numara ile gösterilen bölgeden alınan sonuçlarda bu bölgenin Mn'ca zengin olduğu anlaşılmaktadır. 2 numaralı bölgenin ise matris olan AA7075 alaşımının bileşimi görülmektedir. 
SEM görüntülerinden de anlaşıldığ gibi \% Mn miktarı arttıkça yap1 içerisindeki bulunan Mn çökeltilerinin hacimlerinde bir artış olduğu görülmektedir. Mekanik karıştırma yapılmasına rağmen, ilave edilen Mn'ın homojen bir dağılım sergilemediği ve belirli bölgelerde aglomere olduğu görülmektedir. bunun sebebinin $\mathrm{Mn}$ ve Al tozlarının yoğunluk farkından kaynaklandığı düşünülmektedir 7XXX serisi alüminyum alaşımlarına ilave edilen manganın, $\mathrm{Al}-\mathrm{Zn}-\mathrm{Mg}$ alaşımlarında matris ile bağ oluşturamadığ daha önce yapılan bir çalışmada da vurgulanmaktadır [8]. Farklı oranlarda Mn ilavesi yapılarak üretilen alaşımların sertlik sonuçları Şekil 5'de verilmektedir.

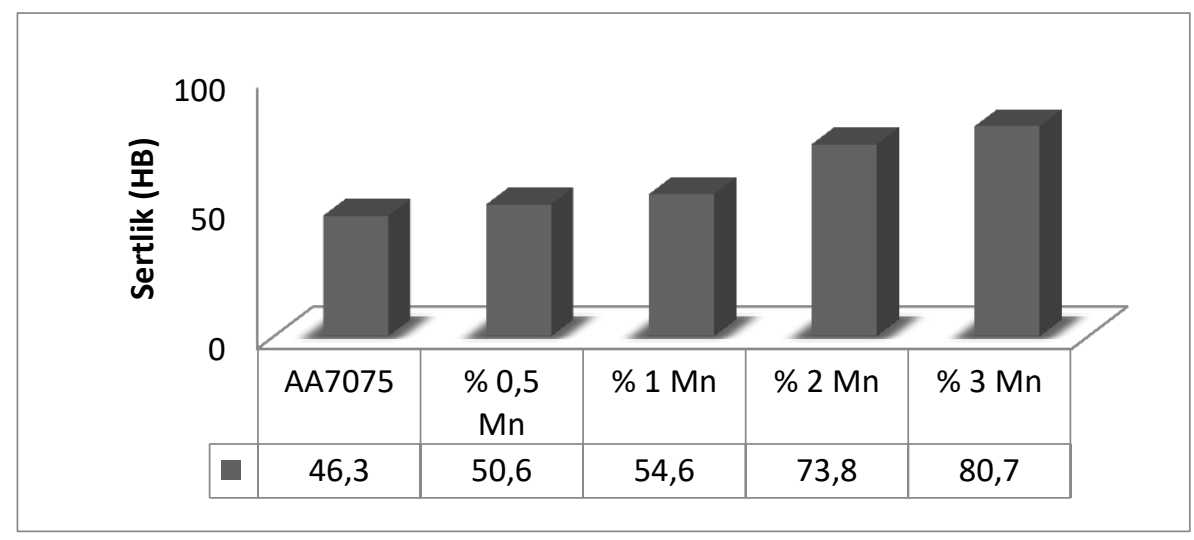

Şekil 5. Farklı miktarlarda Mn ilave edilerek üretilen alaşımların sertlik değerleri. (Hardness values of produced alloys with different amount of Mn)

Yapılan sertlik ölçümleri sonucu en düşük sertlik değeri 46,3 HB ile Mn ilave edilmeyen AA7075 Al alaşımında ölçülürken yapı içerisindeki \% Mn oranı arttıkça sertliğinde arttığı görülmüştür. En yüksek sertlik değeri \% $3 \mathrm{Mn}$ içeren alaşımda ölçülmüştür. Sertlikteki bu artış mekanik karışım sırasında yapı içerisinde Mn parçacıklarının matris içerisinde dağılması sonucu dislokasyon hareketleri engellenmekte ve bu nedenle de alaşımın sertliğinde artış meydana gelmektedir. Alüminyuma Mn ilavesi, alaşıma katı eriyik mukavemetlenmesi sağlamaktadır. Ticari alüminyum alaşımlarına yaklașık \%1.2'ye kadar Mn ilave edildiğinde, orta düzey dayanıma sahip ve 1 sıl işlem uygulanamayan alaşımlar üretilmektedir. 7075 alaşımının en önemli özelliği yaşlandırılabilir olmasıdır. Bu nedenle, bu alaşımlara ilave edilen Mn, yaşlandırılabilirlik özelliği yanında ilaveten, katı eriyik mukavemetlenmesi de sağlamaktadır. Sertlik sonuçları incelendiğinde bu durum daha net olarak da görülmektedir.

Farklı oranlarda Mn ilavesi yapılarak üretilen karışım tozlardan elde edilen numunelerin aşınma testleri sonucu elde edilen ağılık kayıp grafiği Şekil 6a'da aşınma oranları ise Şekil 6b'de verilmektedir.

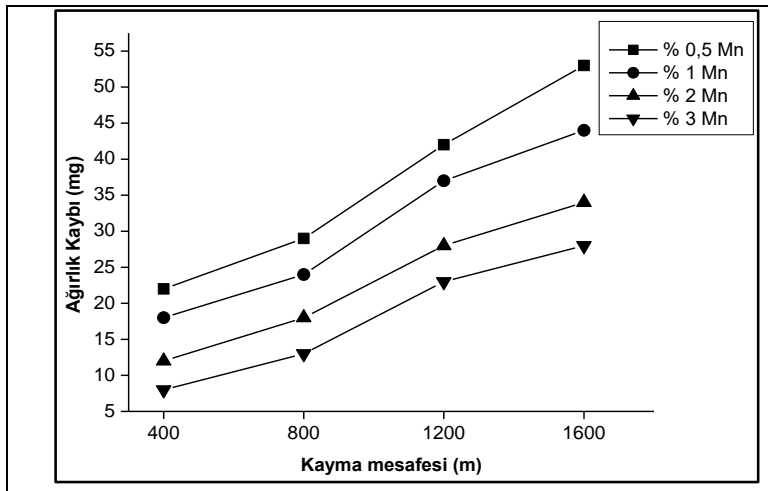

(a)

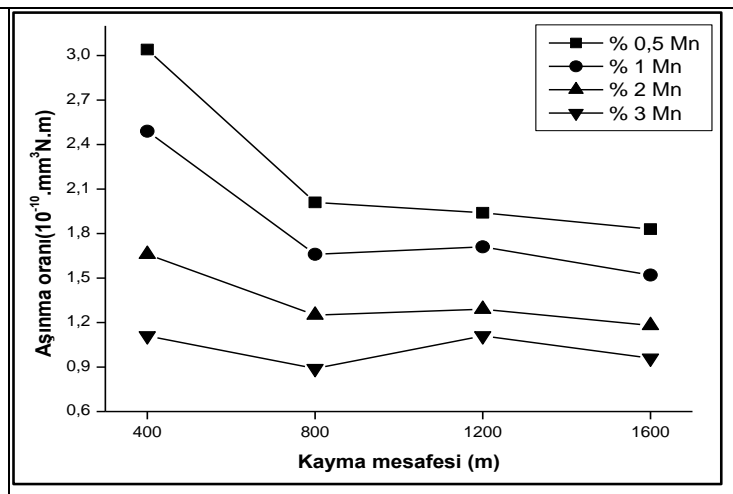

(b)

Şekil 6. Farklı oranlarda Mn ilave edilerek üretilen alaşımların a) ağırlık kaybı b) aşınma oranı( different Mn amount content alloys a) weight loss, $b$ )wear rate) 
Şekil 6 'da verilen ağırlık kaybı sonuçları incelendiğinde, en yüksek ağırlık kaybının \%0.5 Mn ilave edilen alaşımda elde edildiği görülmektedir. Alaşıma ilave edilen Mn miktarı arttıkça 7075+xMn alaşımının ağırlık kaybı azalmaktadır. Bu sonuçlar, Şekil 2'de verilen sertlik sonuçları ile karşılaştırıldığında, aşınma testleri sonrasında elde edilen ağırlık kayıplarının birbirlerini destekledikleri açıkça görülebilir. 7075 alaşımına ilave edilen Mn'ın bir kısmı yapıda çözünerek katı eriyik mukavemetlenmesi sağlarken, çözünmeyen kısmı da yapıda ikinci faz olarak çökelmektedir. Yapıda oluşan ve hem alaşımın kristal kafesinde meydana gelen distorsiyon, hem de Mn çökeltileri dislokasyon hareketini zorlaştırarak alaşımın dayanımına katkı sağlamaktadır. Farklı miktarlarda Mn içeren alaşımların aşınma yüzeyi SEM görüntüleri Şekil 7'de verilmektedir.
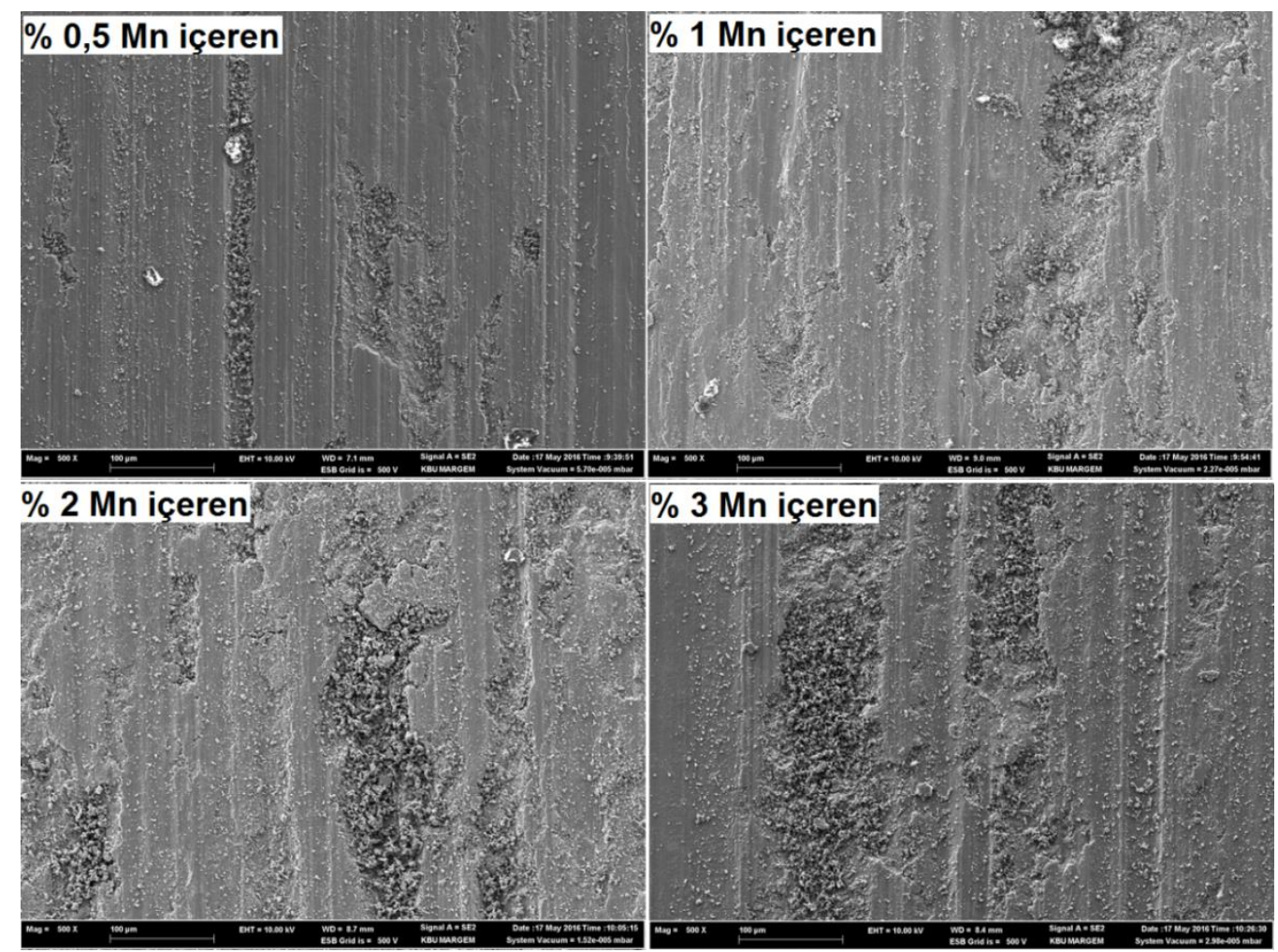

Şekil 7 Farklı oranlarda Mn ilave edilerek üretilen alaşımların aşınma yüzeyi SEM görüntüleri(worn SEM images of produced alloys with different Mn amount.)

Şekil 7'de verilen SEM görüntüleri incelendiğinde kayma yönüne paralel çizikler olduğu net bir şekilde görülmektedir. $\mathrm{Bu}$ çizikler aşınma testi sırasında numune yüzeylerinden kopan parçaların yüzeyleri çizmesinden abrasiv türü bir aşınma mekanizmasının oluştuğu görülmektedir. Ayrıca aşınma sırasında oluşan plastik deformasyon sırasında numuneden kopan bazı parçacıkların numune ve disk arasında kalması ve sürtünme sonucu meydana gelen 1sı yardımıyla tekrar yüzeye yapıştı̆̆ görülmektedir. Bu nedenle, aşınma yüzeylerinde gözlenen yüzey hasarı için hem abrasif hem de adhesiv aşınma mekanizmalarının gerçekleştiği söylenebilir. Ayrıca aşınma yüzeyi SEM görüntülerinde, aşındırılan numunelerin yüzeylerinde kısmi oksidasyon olduğu da görülebilmektedir. Numune yüzeyinde oluşan bu oksitler, kayma sırasında meydana gelen sıcaklık artışı nedeniyle meydana gelmektedir [17]. Kayma sırasında yüzeylerde oluşan bu oksit tabakası, katı yağlayıcı etkisi sağlamaktadır. Bu durum Qi [13] tarafından yapılan bir çalışmada da belirtilmektedir. 


\section{SONUÇ (CONCLUSION)}

Toz metalürjisi yöntemiyle AA7075 alaşımına farklı miktarlarda Mn ilave edilerek üretilen alaşımların mikro yapı sertlik ve aşınma davranışlarının incelendiği bu çalışmada aşağıda verilen sonuçlar elde edilmiştir.

- Mikro yapıda \% Mn miktarı arttıkça yapı içerisindeki bulunan Mn'ca zengin çökeltilerinin hacimlerinde bir artış olduğu mekanik karıştırma yapılmasına rağmen, homojen bir dağılım olmadığı görülmüştür.

- Yapılan sertlik ölçümleri sonucu ilave edilen Mn miktarı arttıkça sertliği artmaktadır.

- Aşınma testleri sonucunda ilave edilen Mn miktarı arttıkça ağılık kaybı ve aşınma oranı azalmaktadır.

\section{KAYNAKLAR (REFERENCES)}

[1] Dursun, T. Soutis C., Recent developments in advanced aircraft aluminium alloys, Materials and Design, 56, 862-871, 2014.

[2] Fakioglu A., Özyürek D., Y1lmaz., R. Effects of different heat treatment conditions on fatigue behavior of AA7075 alloy, High Temperature Materials and Processes, 32(4), 345-351,2013.

[3] Isadare A.D. Aremo, B., Adeoye, M.O, Olawale O.J., Shittu M.D., Effect of heat treatment on some mechanical properties of 7075 aluminium alloy, Materials Research, 16:1(2013) 190-194.

[4]. Özyürek D., Y1lmaz R,. Kibar E., The effect of retrogression parameters in RRA treatment on tensile of 7075 aluminum alloys, Journal of the Faculty of Engineering and Architecture of Gazi University, 27(1), 193-203, 2012.

[5] Deuis R.L., Subramanian C., Yellup J.M., Dry Sliding Wear of Aluminium Composites- A Review, Composites Science. and Technology 57, 415-435, 1997.

[6] How H.C., Baker T.N., Dry sliding wear behaviour of Saffil-reinforced AA6061 composites, Wear 210, 263-272, 1997.

[7] Wang T., Yin Z.M., Shen K., Li J., Huang J.W., Single-Aging Characteristics of 7055 Aluminium Alloy, Transactions of Nonferrous Metals Society of China, 17, 548-552, 2007.

[8] Nam S., Lee D., The effect of Mn on the mechanical behavior of Al alloys, Metals and Materials, 6(1) 13-16, 2000.

[9] Yıldırım M., Özyürek D., Gürü, M. The Effects of Precipitate Size on the Hardness and Wear Behaviors of Aged 7075 Aluminum Alloys Produced by Powder Metallurgy Route, Arabian Journal for Science and Engineering, 41(11) 4273-4281, (2016).

[10] LaDelpha A.D.P., Neubing H., Bishop D.P., Metallurgical assessment of an emerging Al-Zn-Mg-Cu P/M alloy, Materials Science and Engineering A, 520(1-2) 105-113 2009.

[11] Vencl A., Bobic I., Miskovic Z., Effect of Thixocasting and Heat Treatment on the Tribological Properties of Hypoeutectic Al-Si alloy, Wear 264, 616-623, 2008.

[12] Chen R., Iwabuchi A., Shimizu T., The Effect of a T6 Heat Treatment on the Fretting Wear of a SiC Particle-Reinforced A356 Aluminum Alloy Matrix Composite, Wear 238, 110-119, 2000.

[13] Qi W.X., Tu J.P., Liu F.,. Yang Y.Z, Wang N.Y., Lu H.M.,. Zhang X.B,. Guo S.Y,. Liu M.S, Microstructure and Tribological Behavior of a Peak Aged Cu-Cr-Zr Alloy, Materials Science and Engineering, A343, 89-96, 2003. 
[14] Baydoğan M., Çimenoğlu H., Kayalı E.S., A Study on Sliding Wear of a 7075 Aluminum alloy, Wear, 257, 852-861, 2004.

[15] Ceschini L., Bosi C., Casagrande A., Garagnani G.L., Effect of Thermal Treatment and Recycling on the Tribological Behaviour of an AlSiMg-SiCp Composite, Wear, 251, 1377-1388, 2001.

[16] Mindivan H.,. Kayali E. S, Cimenoglu H., Tribological Behavior of Squeeze Cast Aluminum Matrix Composites, Wear, 265, 645-654. 2008.

[17] Özyürek D., Çiftci İ., Tuncay T., The effect of aging and sliding speed on wear behaviour of Cu-CrZr alloy, Materials Testing, 55(6) 468-471, 2013. 